\title{
Infant-sibling Interactions: A Window to the Intergenerational Transmission of Caregiving Behaviors
}

\author{
By Tywanquila Walker*
}

\begin{abstract}
Infant-sibling interactions were examined as a mechanism for understanding the development of responsive caregiving behaviors in older siblings. Twelve-month-old infants $(M=12.5$ months $)$, their 3-to 10-year-old siblings $(M=5$ years $)$, and their mothers ( $n=26$ infant-sibling-mother triads) were observed during separate 20minute infant-sibling and infant-mother interactions. Responsiveness to infant behaviors was analyzed using seven mutually exclusive, non-culture-specific vocal and non-vocal categories and sequential data analysis. The onset of caregiving behaviors was age-related, with siblings' responsiveness levels increasing and resembling mothers' responsiveness levels after age six. Infant-sibling interactions, non-culture-specific coding, and sequential analysis provide new techniques for examining familial interactions and the trajectory of intergenerational transmission as a function of child age and caregiver behaviors.
\end{abstract}

Keywords: Caregiving behaviors, Intergenerational transmission, Sequential data analysis, Siblings, Social learning.

\section{Introduction}

Through observational learning, children actively imitate attitudes and behaviors that their parents may not have intentionally tried to teach them (Bandura and Huston 1961). Over the last several decades, the strong association between unintentionally taught negative parenting behaviors and the continuity of these behaviors in future generations has become an issue of great concern to researchers, policy makers, and family and child practitioners (e.g., Bailey et al. 2009, DuMont et al. 2008, Neppl et al. 2009, Seay et al. 2016). As a result, research regarding the intergenerational transmission of caregiving behaviors has focused on abusive child-parent relationships and the generational effects of harsh parenting (Simons et al. 1991).

These studies show that there is intergenerational continuity in parenting behavior (Putallaz et al. 1998) and that mothers and fathers communicate their parenting beliefs indirectly through their parenting practices (i.e., beliefs about physical discipline are conveyed through threats and corporal punishment; Simons et al. 1993, see also Schofield and Weaver 2016). However, one limitation of the traditional approach is the difficulty of determining the developmental trajectory of intergenerational transmission. For example, at what age do children

\footnotetext{
* Department of Psychology, Cornell University and Department of Psychology, Rochester Institute of Technology, USA.
} 
first demonstrate intergenerationally-transmitted behaviors? How do we measure these behavioral changes in real time? A second limitation is that intergenerational methodologies primarily focus on the parent and not the real-time learning of the child.

Despite these limitations, intergenerational transmission studies which take into account the long-term effects that parenting behaviors have on children suggest that children use the negative parenting behaviors of their parents as models for their own parenting behaviors (Serbin and Karp 2003). These studies generally focus on the behavioral and cognitive problems that result from learning negative behaviors and fail to address the mechanisms that lead to the transmission of these behaviors; nor do they address how constructive parenting behaviors affect children. Furthermore, because many intergenerational transmission studies focus on young adults (Chen and Kaplan 2001) and are retrospective (Simons et al. 1991), they require individuals to think back to their childhood experiences and extrapolate the trajectory of their current parenting behaviors. Thus, it is difficult to assess the real-time processes by which caregiving behaviors are acquired. In contrast, the current study addresses these issues by using infant-sibling interactions as a mechanism for examining the development and intergenerational transmission of caregiving behaviors. Secondly, we focus specifically on constructive caregiving behaviors - an area of which we have limited knowledge.

According to social learning theory, children learn their behaviors from important adults with whom they identify (e.g., parents; Bandura and Huston 1961, Bandura et al. 1961). Given that social learning theory is applicable to the intergenerational transmission of parenting behaviors - and that children who live in a household with a parent and an infant sibling are provided with numerous opportunities to observe how the infant-caregiver dyad interact - the result of these observations should be manifested in proximal infant-sibling interactions in which the child models his or her caregiver. Proximal interactions are interactions that occur when participants occupy the same space and are able to see each other. Due to the physical nearness of participants, proximal interactions provide the opportunity to assess caregiver responses sequentially as they relate to the behavior of the infant. Furthermore, these responses are dependent on the actions of both the parent and the infant; the actions of one are influenced by the actions of the other. Because responses are measured in real-time (as opposed to retrospective), the development of caregiving behaviors in older siblings can be studied in detail without being subject to retrospective memory limitations.

\section{Proximal Interactions and Siblings}

Unlike other categories of caregiving behaviors, proximal response behaviors can also be used to assess how siblings respond to infants. For example, the use of the categories authoritarian, authoritative, permissive, and neglectful (Baumrind 1991) may be helpful for categorizing caregiving behaviors. However, as ways to define an infant-sibling interaction, use of these categories is inappropriate 
because they: 1) imply that caregiving behaviors are stable over time (i.e., there is no developmental change of caregiving behaviors) and 2) suggest that a sibling is responsible for disciplining an infant. In contrast, the proximal approach allows for changes in caregiving behaviors. It does not assume that caregiving behaviors are unidirectional and that only the caregiver's responses are important for analyzing caregiving behaviors. Instead, the proximal approach takes into account how the infant's behavior affects the caregiving response as well as how that response shapes the infant's subsequent behavior; it is a bidirectional model, which accounts for infant effects.

Three aspects of proximal parenting behaviors - promptness, contingency, and appropriateness - have been shown to impact the language learning of 9and 13-month-old infants (Tamis-LeMonda and Bornstein 2002, see also Haebig et al. 2013). Promptness is the latency of the caregiver's response to infant vocalizations. A contingent caregiver response is one that is dependent on the infant's behavior at a specific point in time during a period of shared attention. Appropriateness refers to a positive response that is relevant to the infant's behavior (e.g., an infant picks up a ball and the parent labels the toy as "ball"). This proximal approach can also be used to track the trajectory of the development of caregiving behaviors. Together, these three behaviors comprise what we will hereafter refer to as a responsive behavior (i.e., a responsive behavior is a caregiving response that is prompt, contingent, and appropriate to the infant's previous behavior).

During live interactions, the promptness, contingency, and appropriateness of sibling responses can be observed and thus provide more specific and reliable measures of the caregiving behaviors of siblings over time. Furthermore, these proximal mechanisms can be studied in children of different ages and used to construct a timeline of the development of caregiving behaviors. By identifying the mechanisms of intergenerational transmission, one can determine which caregiving behaviors facilitate the learning of both positive and negative behaviors as well as how, and when, children of different ages use those mechanisms.

\section{Links between Prosocial Behaviors and Caregiving Behaviors}

Investigations of preschoolers' interactions with infants suggest that there is a gradual onset of caregiving behavior. For example, children younger than 3 or 4 years generally have trouble attending to infant states and participating in multi-speaker turn taking interactions (Casillas 2014, Dunn and Shatz 1989, Howe 1991, Shatz and Gelman, 1973); at 18 months they are capable of sharing, helping, and comforting their siblings, but rarely respond in these ways (Dunn and Munn 1986). By age 4, older siblings use shorter utterances and more simplified speech when communicating with infants (Shatz and Gelman 1973). Furthermore, as children get older, they begin to display more prosocial behaviors towards their siblings.

Eisenberg et al. $(1983,1987)$ conducted a longitudinal study which showed that between the ages of 4 and 12 years, hedonistic (self-focused) reasoning 
decreases while direct reciprocity, role-taking, and approval-oriented reasoning increases. By age 9, children begin to use sympathetic reasoning and are more likely to consider situational factors when resolving moral dilemmas (Eisenberg et al. 1983, 1987). Given that children's display of prosocial behaviors increases with age, their ability to produce responsive caregiving behaviors should also be age-related. Examining infant-sibling proximal interactions as they relate to prosocial and caregiving behaviors can be advantageous to the development of early childhood interventions and child abuse prevention programs because they serve as early markers for the intergenerational transmission of parenting behaviors.

Family members are part of an interdependent, interactive network in which the behavior of each individual modifies the behavior of other individuals in the family (Hetherington 1994). Thus, research on familial interactions can have broad impacts on several communicative and social issues, including the effects of parental behaviors on children's long-term positive developmental outcomes as well as how older children communicate with younger siblings (Zukow-Goldring 2002). Currently, it is unclear when children begin acquiring caregiving behaviors or how these behaviors are manifested in interactions with others, particularly younger siblings. One key to determining how to prevent negative infant-caregiver relationships is to first understand when caregiving behaviors develop. By studying infant-sibling interactions in a more in-depth manner, we can pinpoint when children begin to acquire caregiving behaviors and track the development of these behaviors over the course of a lifespan - from childhood to adulthood.

\section{The Current Study}

Given that behaviors are intergenerationally transmitted and children model the behaviors of their caregivers (Leaper 2000, 2002, Madden et al. 2015, Neppl et al. 2009, Serbin and Karp 2003), the current study focused on the development of caregiving behaviors via observation of infant-sibling and infant-caregiver interactions. More specifically, we examined whether sibling behaviors resemble those of their mothers when siblings communicate with infants. We also investigated infant-caregiver and infant-sibling engagement by analyzing the promptness, appropriateness, and contingency of infant-directed responses. Twelve-month-old infants were recruited because caregiver responsiveness around this age predicts linguistic and cognitive development (Haebig et al. 2013, Tamis-LeMonda and Bornstein 2002). Secondly, locomoting infants create more opportunities for social interactions.

The purpose of this research was to study the siblings of infants and assess the developmental trajectory of responsive caregiving behaviors in 3- to 10year-old children. The current research, with its focus on the development of caregiving, represents a new initiative in the study of the intergenerational transmission of parenting behaviors. By determining the age at which children begin to display responsive caregiving behaviors and how their interactions with infants come to resemble those of their parents, we can better understand how to recognize and promote the transmission of positive parenting behaviors. 


\section{Method}

\section{Participants}

Twenty-two infants participated in this study. Three infants had 2 or more older siblings who also participated, which resulted in a final sample of 26 infant-sibling-mother triads. The triads consisted of 12-month-old infants $(M=$ 12.5 months, $S D=1.21)$, their 3- to 10 -year-old siblings $(M=5$ years, $S D=$ 1.96 years), and their mothers ( $M=35.8$ years, $S D=4.86$; age range $24-44$ years). Older sibling age and gender and infant gender are listed in 
Table $1.72 .7 \%$ of the mothers were white, $4.5 \%$ were black, and $22.7 \%$ were either multi-racial or of other ethnicities. All of the mothers were living with a spouse or partner. All of the mothers except one were married. The average age of the spouse/ partner was 37.5 years (age range 29-44 years, $S D=4.61$ ).

Participants were recruited through a letter given to caregivers at the time of the infant's birth. Caregivers interested in participating in studies on infant learning and development were added to a database. These caregivers were sent a second letter when their infants were near 12 months of age, followed by a telephone call to schedule an appointment. The infant age group was held constant because we wanted older siblings to have similar amounts of experience with the infants (i.e., approximately 12 months of experience both interacting with the infant and observing the caregiver interact with the infant). Additionally, we chose this age group because older infants are able to locomote independently, which affords them the opportunity to both initiate interactions and respond to others' behaviors.

Due to experimenter error, the interaction data of one mother was omitted from this study; the sibling data for this family was used for age-group comparisons, but not for sibling-mother comparisons. Two additional infantsibling-mother triads were tested and subsequently omitted; one due to experimenter error and one because the children were step-siblings and did not live in the same household, nor did they see each other often enough to provide the older child with an opportunity to observe the mother interacting with the infant. All infants received a t-shirt, sippy cup, or bib in appreciation for their participation; older siblings received a t-shirt, toy, or stickers. 
Table 1. Older Sibling Age and Gender and Infant Gender

\begin{tabular}{|c|c|c|}
\hline Older Sibling Age & Older Sibling Gender & Infant Gender \\
\hline $2 ; 10^{*}$ & Female & Female \\
\hline $3 ; 1$ & Male & Female \\
\hline $3 ; 1$ & Male & Female \\
\hline $3 ; 5$ & Male & Female \\
\hline $3 ; 5$ & Male & Male \\
\hline $3 ; 7$ & Male & Male \\
\hline $3 ; 9^{\dagger}$ & Female & Female \\
\hline $3 ; 9$ & Male & Male \\
\hline $3 ; 11$ & Female & Female \\
\hline $4 ; 2$ & Female & Female \\
\hline $4 ; 2$ & Female & Female \\
\hline $4 ; 5$ & Male & Female \\
\hline $4 ; 5$ & Female & Male \\
\hline $4 ; 6$ & Male & Female \\
\hline $4 ; 7$ & Male & Female \\
\hline $4 ; 10$ & Female & Female \\
\hline $5 ; 0$ & Female & Male \\
\hline $5 ; 1$ & Male & Female \\
\hline $5 ; 2$ & Female & Female \\
\hline $5 ; 10$ & Female & Male \\
\hline $6 ; 2^{\dagger}$ & Male & Female \\
\hline $6 ; 6$ & Male & Female \\
\hline $7 ; 3^{\ddagger}$ & Female & Female \\
\hline $8 ; 10^{\ddagger}$ & Female & Female \\
\hline $9 ; 2^{*}$ & Male & Female \\
\hline $10 ; 3^{\sharp}$ & Female & Female \\
\hline Mean = 5;1 & 13 males, 13 females & 6 males, 20 females \\
\hline
\end{tabular}

$* \dagger \ddagger$ denote siblings from same family

\section{Materials and Apparatus}

The study was conducted in a large playroom. Various colorful and engaging toys (e.g., stacking cups, balls, cloth blocks) were placed on the floor of the playroom. The center of the room was completely free of obstacles (e.g., tables, chairs), which gave the participants freedom to move around the room as they chose. Infant-mother and infant-sibling interactions were recorded using a Canon FS200 video camera. The videos were later digitized, saved onto a Mac computer, and coded using EventCoder software (Goldstein and Brodsky 2006).

Mothers completed a family demographic survey that contained questions about the parents, the sibling, the infant, and the number of people in the household. The demographic survey was administered as a paper-based survey and included an assessment of socio-economic status based on occupation, information about the number of children in the household, and marital status. The parent portions of the survey included questions about the amount of time 
per week the parent spent with the infant and hours of employment per week. The sibling portion of the survey assessed the amount of time per week the sibling spent with the infant, the number of hours per week the sibling spent at home, in daycare, or in school, and the gender of the sibling. The infant portion of the survey included the number of hours per week the infant spent at home, in daycare or with a babysitter, and the infant's gender. The survey contained open-ended questions (e.g., Do you work outside the home?; What is your occupation?; How many hours per week do you spend at work?; How many hours per week does your older child spend with your infant?; How many hours per week does your older child spend at school?; How many hours per week does your infant spend in daycare?) and multiple-choice questions (e.g., What is your marital status?: Married, Separated, Divorced, Widowed, Never Married, Cohabitating with a Romantic Partner; How many times a week does your older child read to your infant?: Not at All, 1 or 2, 3 to 6, Every Day).

\section{Procedure}

Participants' interactions were recorded during two 20-minute unstructured play sessions. In the infant-mother session, the mother and the infant were provided with toys and asked to play as they normally would at home. To prevent on-the-spot learning, the sibling was not present and instead played with a research assistant in another room. Thus, the sibling was unable to observe the infant-mother interaction. In the infant-sibling session, the sibling and the infant played together while the mother sat in a chair in the corner of the room and completed the family demographic survey. First, the mother was instructed to encourage the older sibling to play with the infant. Then, she was asked to remain as quiet as possible and not to interrupt the children while they played unless she felt it was necessary for her to intervene (e.g., the infant cried and the older sibling was unable to console him/her). Siblings were simply asked to play with the infant; they were not given additional instructions. The order of the infant-mother session and the infant-sibling session was counterbalanced across participants.

\section{Coding}

The 20-minute play sessions were coded for infant behaviors and the corresponding behaviors of mothers and older siblings. Mother and sibling responsiveness were coded using a system derived from the coding schemes of Gros-Louis et al. (2006), Bornstein et al. (1992), and Vollmer (2007). Infant, mother, and sibling behaviors were classified into the following mutually exclusive categories: object-related non-vocal, object-related vocal, dyadic non-vocal, dyadic vocal, distress vocalizations (e.g., crying; for infants only), and other verbal and vocal behaviors (Table 2). To ensure that the categories were mutually exclusive, if more than one behavior occurred at the same time, the activity that captured the infant's immediate attention was coded. For example, if an infant vocalized while giving an object to the mother, the 
infant's eye gaze was used to determine if the behavior was object-related or dyadic. Additionally, distress vocalizations took precedence over all other categories. These measures were chosen because they have proven to be reliable measures of responsiveness in previous studies (e.g., Bornstein et al. 1992, Vollmer 2007).

Table 2. Descriptions of the Seven Mutually-Exclusive Categories Used to Classify Infant, Mother, and Sibling Behaviors

\begin{tabular}{|l|l|}
\hline Behavior & \multicolumn{1}{c|}{ Description } \\
\hline Object-related non-vocal & $\begin{array}{l}\text { Non-verbal behaviors that involve an object (e.g., } \\
\text { manipulating, showing, pointing at, looking at, or } \\
\text { getting a toy) }\end{array}$ \\
\hline Object-related vocal & $\begin{array}{l}\text { a. Infant: Any category 1 behavior paired with a } \\
\text { vocalization that refers to the object (e.g., infant } \\
\text { makes an object-directed vocalization while looking } \\
\text { at a ball) } \\
\text { b. Mother/Sibling: Any category 1 behavior paired } \\
\text { with a vocalization that refers to the object; must be } \\
\text { attempting to reorganize the infant's attention } \\
\text { towards the object (e.g., infant makes an object- } \\
\text { related vocalization while looking at a ball; mother } \\
\text { says, "Look at the ball!") }\end{array}$ \\
\hline Dyadic non-vocal & $\begin{array}{l}\text { Face-to-face interaction that involves eye contact } \\
\text { and/or physical contact (e.g., touching) }\end{array}$ \\
\hline Dyadic vocal & $\begin{array}{l}\text { Any category 3 behavior paired with a non-cry } \\
\text { vocalization (e.g., babbling, cooing, talking) }\end{array}$ \\
\hline $\begin{array}{l}\text { Distress vocalization } \\
\text { (coded only for infants) }\end{array}$ & \begin{tabular}{l} 
Crying or extreme fussing \\
\hline Other vocal
\end{tabular} \\
\hline $\begin{array}{l}\text { Other object-related non- } \\
\text { vocal (coded only for } \\
\text { mothers and siblings) }\end{array}$ & $\begin{array}{l}\text { Any vocalization that does not fit within the above } \\
\text { vocal categories (i.e., object-related vocal, dyadic } \\
\text { vocal, distress vocalization) }\end{array}$ \\
\hline
\end{tabular}

Mother and sibling behaviors were only credited as responsive if they 1) occurred immediately after the infant's behavior, 2) occurred within 5 seconds of the infant's preceding behavior (Bornstein et al. 1992), and 3) were relevant to the infant's behavior (i.e., prompt, contingent, and appropriate). If the infant performed multiple consecutive behaviors before the sibling or mother responded, the sibling or mother was only credited with responding to the last behavior. For example, if the infant emitted three vocalizations in a row and the mother only responded to the third vocalization, the mother would be considered $33 \%$ responsive. If, on the other hand, the mother responded after every infant vocalization, the mother would be considered $100 \%$ responsive. Sibling and mother responses did not have to match the infant behavior. For example, if an infant performed an object-related behavior, the sibling's responding behavior did not have to be object-related as well. As long as sibling 
and mother responses met the three previously mentioned criteria, they could respond with any of the behaviors and be credited as responsive. Given that other vocal and other object-related non-vocal behaviors did not involve interaction with the infant and were not based on the infant's actions, they were not credited as responsive behaviors.

\section{Intercoder Reliability}

There were four coders for this study. Prior to coding for this study, each coder completed six to ten hours of video-coder training; the author trained all coders. Training consisted of coding three 20-minute practice videos, which consisted of two infant-mother play sessions and one infant-sibling play session. Practice videos were chosen such that the mothers and sibling varied in levels of responsiveness and types of caregiving behaviors. Throughout training (i.e., before, during, and after practice coding sessions), coders and the author discussed the behavior categories and how each infant, mother, and sibling behavior should be coded. After each practice video was coded, the author compiled a spreadsheet and showed the coders their reliability measures. Reliability was calculated using percent agreement. Discrepancies were discussed and, if necessary, the practice videos were recoded. When intercoder reliability reached greater than $90 \%$ for the third practice video, coding began for the current study.

On average, it took coders 1 to 1.5 hours to code a 20 -minute video. To check intercoder reliability, two videos were selected for recoding. The first 10 minutes of each video was recoded, which resulted in 20 minutes of recordings for reliability checks. Percent agreement for the recoded videos ranged from $80 \%$ to $98 \%$. Intercoder reliability was also measured by computing intraclass correlation coefficients (ICC). ICCs ranged from .70 to .98. Coder 1 coded $45 \%$ of the videos. Coder 2 coded $19 \%$ of the videos. Coder 3 coded $19 \%$ of the videos. Coder 4 coded $17 \%$ of the videos.

\section{Results}

\section{Level of Responsiveness}

Sibling and mother level of responsiveness to each infant behavior was analyzed. Level of responsiveness was calculated as the number of times a sibling or mother responded to a behavior divided by the number of times the infant performed the behavior; thus, level of responsiveness was calculated as a proportion (e.g., 88 mother responses/157 infant objected-related vocalizations $=.56$ level of responsiveness to infant object-related vocalizations). Overall level of responsiveness was calculated by dividing the sum of all sibling or mother responses by the sum of all infant behaviors (i.e., [sum of all the times the sibling/mother responded to an infant behavior]/[sum of all infant behaviors] = Overall Responsiveness; e.g., [mother responded to 88 object-related non-vocal 
+34 object-related vocal +8 dyadic non-vocal +3 dyadic vocal $] /[157$ objectrelated non-vocal +50 object-related vocal +8 dyadic non-vocal +3 dyadic vocal infant behaviors] results in [133 mother responses]/[218 infant behaviors] = .61 overall responsiveness).

Multivariate Analysis of Covariance (MANCOVA) was used to control for older siblings who were from the same family (see Table 1). Family was coded using weighted effect coding to account for the unequal sample sizes of singlesibling participants $(n=19)$ and multi-sibling participants $(n=7)$. The effect of sibling age on level of responsiveness for each infant behavior was analyzed. The independent variable, age, included nine levels: older sibling ages 3, 4, 5, $6,7,8,9$, and 10 years and the mother (i.e., the levels were categorical; the mothers' ages were not further defined into categories). The five dependent variables were the level of responsiveness to each infant behavior: infant object-related non-vocal responsiveness; infant object-related vocal responsiveness; infant dyadic non-vocal responsiveness; infant dyadic vocal responsiveness; and overall responsiveness (see Table 3 for descriptive statistics of infant behaviors, responses, and level of responsiveness by age). Preliminary analyses evaluating the assumption of homogeneity of regression slopes for the MANCOVA indicated there was not an interaction between age and family; thus, the assumption was supported for level of responsiveness for all infant behaviors (all $p>.255)$.

Table 3. Descriptive Statistics for Infant Behaviors, Response to Infant Behaviors, and Sibling/Mother Level of Responsiveness by Age

\begin{tabular}{|c|c|c|c|c|c|c|}
\hline & Age & $n$ & Minimum & Maximum & Mean & $\begin{array}{l}\text { Standard } \\
\text { Deviation }\end{array}$ \\
\hline \multirow{9}{*}{$\begin{array}{l}\text { Number of Infant Behaviors: } \\
\text { Infant Object-Related Non-Vocal }\end{array}$} & 3 & 9 & 21 & 222 & 97.00 & 68.83 \\
\hline & 4 & 7 & 74 & 190 & 120.14 & 44.76 \\
\hline & 5 & 4 & 40 & 910 & 361.00 & 383.07 \\
\hline & 6 & 2 & 45 & 144 & 94.50 & 70.00 \\
\hline & 7 & 1 & 140 & 140 & 140.00 & \\
\hline & 8 & 1 & 102 & 102 & 102.00 & \\
\hline & 9 & 1 & 40 & 40 & 40.00 & \\
\hline & 10 & 1 & 114 & 114 & 114.00 & \\
\hline & Mother & 21 & 50 & 637 & 203.86 & 174.56 \\
\hline \multirow{9}{*}{$\begin{array}{l}\text { Number of Times Sibling/Mother } \\
\text { Responded to Infant Object- } \\
\text { Related Non-Vocal }\end{array}$} & 3 & 9 & 0 & 21 & 5.11 & 6.41 \\
\hline & 4 & 7 & 1 & 35 & 12.00 & 12.07 \\
\hline & 5 & 4 & 6 & 24 & 11.25 & 8.54 \\
\hline & 6 & 2 & 5 & 12 & 8.50 & 4.95 \\
\hline & 7 & 1 & 40 & 40 & 40.00 & \\
\hline & 8 & 1 & 48 & 48 & 48.00 & \\
\hline & 9 & 1 & 34 & 34 & 34.00 & \\
\hline & 10 & 1 & 56 & 56 & 56.00 & \\
\hline & Mother & 21 & 24 & 316 & 100.90 & 81.09 \\
\hline
\end{tabular}




\begin{tabular}{|c|c|c|c|c|c|c|}
\hline \multirow{9}{*}{$\begin{array}{l}\text { Level of Responsiveness: Infant } \\
\text { Object-Related Non-Vocal } \\
\text { Responsiveness }\end{array}$} & 3 & 9 & 0.00 & 0.19 & 0.07 & 0.06 \\
\hline & 4 & 7 & 0.01 & 0.20 & 0.09 & 0.07 \\
\hline & 5 & 4 & 0.01 & 0.18 & 0.09 & 0.08 \\
\hline & 6 & 2 & 0.08 & 0.11 & 0.10 & 0.02 \\
\hline & 7 & 1 & 0.29 & 0.29 & 0.29 & \\
\hline & 8 & 1 & 0.47 & 0.47 & 0.47 & \\
\hline & 9 & 1 & 0.85 & 0.85 & 0.85 & \\
\hline & 10 & 1 & 0.49 & 0.49 & 0.49 & \\
\hline & Mother & 21 & 0.25 & 0.76 & 0.53 & 0.13 \\
\hline \multirow{9}{*}{$\begin{array}{l}\text { Number of Infant Behaviors: } \\
\text { Infant Object-Related Vocal }\end{array}$} & 3 & 9 & 0 & 109 & 38.67 & 42.32 \\
\hline & 4 & 7 & 7 & 23 & 13.86 & 7.97 \\
\hline & 5 & 4 & 0 & 33 & 18.25 & 16.32 \\
\hline & 6 & 2 & 34 & 69 & 51.50 & 24.75 \\
\hline & 7 & 1 & 57 & 57 & 57.00 & \\
\hline & 8 & 1 & 109 & 109 & 109.00 & \\
\hline & 9 & 1 & 35 & 35 & 35.00 & \\
\hline & 10 & 1 & 31 & 31 & 31.00 & \\
\hline & Mother & 21 & 5 & 215 & 58.10 & 49.12 \\
\hline \multirow{9}{*}{$\begin{array}{l}\text { Number of Times Sibling/Mother } \\
\text { Responded to Infant Object- } \\
\text { Related Vocal }\end{array}$} & 3 & 9 & 0 & 12 & 3.11 & 3.98 \\
\hline & 4 & 7 & 0 & 5 & 1.86 & 2.27 \\
\hline & 5 & 4 & 0 & 6 & 1.50 & 3.00 \\
\hline & 6 & 2 & 11 & 13 & 12.00 & 1.41 \\
\hline & 7 & 1 & 29 & 29 & 29.00 & \\
\hline & 8 & 1 & 53 & 53 & 53.00 & \\
\hline & 9 & 1 & 30 & 30 & 30.00 & \\
\hline & 10 & 1 & 19 & 19 & 19.00 & \\
\hline & Mother & 21 & 4 & 81 & 31.95 & 22.42 \\
\hline \multirow{9}{*}{$\begin{array}{l}\text { Level of Responsiveness: Infant } \\
\text { Object-Related Vocal } \\
\text { Responsiveness }\end{array}$} & 3 & 9 & 0.00 & 0.32 & 0.08 & 0.10 \\
\hline & 4 & 7 & 0.00 & 0.23 & 0.12 & 0.11 \\
\hline & 5 & 4 & 0.00 & 0.19 & 0.05 & 0.10 \\
\hline & 6 & 2 & 0.16 & 0.38 & 0.27 & 0.16 \\
\hline & 7 & 1 & 0.51 & 0.51 & 0.51 & \\
\hline & 8 & 1 & 0.49 & 0.49 & 0.49 & \\
\hline & 9 & 1 & 0.86 & 0.86 & 0.86 & \\
\hline & 10 & 1 & 0.61 & 0.61 & 0.61 & \\
\hline & Mother & 21 & 0.24 & 0.92 & 0.61 & 0.20 \\
\hline \multirow{3}{*}{$\begin{array}{l}\text { Number of Infant Behaviors: } \\
\text { Infant Dyadic Non-Vocal }\end{array}$} & 3 & 9 & 0 & 0 & 0.00 & 0.00 \\
\hline & 4 & 7 & 0 & 5 & 1.29 & 2.21 \\
\hline & 5 & 4 & 0 & 5 & 1.50 & 2.38 \\
\hline
\end{tabular}




\begin{tabular}{|c|c|c|c|c|c|c|}
\hline & 6 & 2 & 0 & 2 & 1.00 & 1.41 \\
\hline & 7 & 1 & 0 & 0 & 0.00 & \\
\hline & 8 & 1 & 0 & 0 & 0.00 & \\
\hline & 9 & 1 & 0 & 0 & 0.00 & \\
\hline & 10 & 1 & 1 & 1 & 1.00 & \\
\hline & Mother & 21 & 0 & 41 & 6.62 & 11.10 \\
\hline \multirow{9}{*}{$\begin{array}{l}\text { Number of Times Sibling/Mother } \\
\text { Responded to Infant Dyadic } \\
\text { Non-Vocal }\end{array}$} & 3 & 9 & 0 & 0 & 0.00 & 0.00 \\
\hline & 4 & 7 & 0 & 3 & 0.57 & 1.13 \\
\hline & 5 & 4 & 0 & 3 & 1.00 & 1.41 \\
\hline & 6 & 2 & 0 & 1 & 0.50 & 0.71 \\
\hline & 7 & 1 & 0 & 0 & 0.00 & \\
\hline & 8 & 1 & 0 & 0 & 0.00 & \\
\hline & 9 & 1 & 0 & 0 & 0.00 & \\
\hline & 10 & 1 & 1 & 1 & 1.00 & \\
\hline & Mother & 21 & 0 & 33 & 4.71 & 8.43 \\
\hline \multirow{9}{*}{$\begin{array}{l}\text { Level of Responsiveness: Infant } \\
\text { Dyadic Non-Vocal } \\
\text { Responsiveness }\end{array}$} & 3 & 9 & 0.00 & 0.00 & 0.00 & 0.00 \\
\hline & 4 & 7 & 0.00 & 0.60 & 0.12 & 0.23 \\
\hline & 5 & 4 & 0.00 & 1.00 & 0.40 & 0.49 \\
\hline & 6 & 2 & 0.00 & 0.50 & 0.25 & 0.35 \\
\hline & 7 & 1 & 0.00 & 0.00 & 0.00 & \\
\hline & 8 & 1 & 0.00 & 0.00 & 0.00 & \\
\hline & 9 & 1 & 0.00 & 0.00 & 0.00 & \\
\hline & 10 & 1 & 1.00 & 1.00 & 1.00 & \\
\hline & Mother & 21 & 0.00 & 1.00 & 0.44 & 0.41 \\
\hline \multirow{9}{*}{$\begin{array}{l}\text { Number of Infant Behaviors: } \\
\text { Infant Dyadic Vocal }\end{array}$} & 3 & 9 & 0 & 1 & 0.22 & 0.44 \\
\hline & 4 & 7 & 0 & 11 & 2.00 & 4.12 \\
\hline & 5 & 4 & 0 & 44 & 12.75 & 20.93 \\
\hline & 6 & 2 & 0 & 0 & 0.00 & 0.00 \\
\hline & 7 & 1 & 0 & 0 & 0.00 & \\
\hline & 8 & 1 & 0 & 0 & 0.00 & \\
\hline & 9 & 1 & 103 & 103 & 103.00 & \\
\hline & 10 & 1 & 1 & 1 & 1.00 & \\
\hline & Mother & 21 & 0 & 136 & 15.62 & 30.37 \\
\hline
\end{tabular}




\begin{tabular}{|c|c|c|c|c|c|c|}
\hline \multirow{9}{*}{$\begin{array}{l}\text { Number of Times Sibling/Mother } \\
\text { Responded to Infant Dyadic } \\
\text { Vocal }\end{array}$} & 3 & 9 & 0 & 0 & 0.00 & 0.00 \\
\hline & 4 & 7 & 0 & 5 & 0.86 & 1.86 \\
\hline & 5 & 4 & 0 & 21 & 5.50 & 10.34 \\
\hline & 6 & 2 & 0 & 0 & 0.00 & 0.00 \\
\hline & 7 & 1 & 0 & 0 & 0.00 & \\
\hline & 8 & 1 & 0 & 0 & 0.00 & \\
\hline & 9 & 1 & 71 & 71 & 71.00 & \\
\hline & 10 & 1 & 1 & 1 & 1.00 & \\
\hline & Mother & 21 & 0 & 94 & 11.48 & 21.26 \\
\hline \multirow{9}{*}{$\begin{array}{l}\text { Level of Responsiveness: Infant } \\
\text { Dyadic Vocal Responsiveness }\end{array}$} & 3 & 9 & 0.00 & 0.00 & 0.00 & 0.00 \\
\hline & 4 & 7 & 0.00 & 0.45 & 0.11 & 0.20 \\
\hline & 5 & 4 & 0.00 & 0.50 & 0.24 & 0.28 \\
\hline & 6 & 2 & 0.00 & 0.00 & 0.00 & 0.00 \\
\hline & 7 & 1 & 0.00 & 0.00 & 0.00 & \\
\hline & 8 & 1 & 0.00 & 0.00 & 0.00 & \\
\hline & 9 & 1 & 0.69 & 0.69 & 0.69 & \\
\hline & 10 & 1 & 1.00 & 1.00 & 1.00 & \\
\hline & Mother & 21 & 0.00 & 1.00 & 0.55 & 0.40 \\
\hline \multirow{9}{*}{$\begin{array}{l}\text { Level of Responsiveness: Overall } \\
\text { Responsiveness }\end{array}$} & 3 & 9 & 0.00 & 0.16 & 0.06 & 0.05 \\
\hline & 4 & 7 & 0.03 & 0.23 & 0.10 & 0.08 \\
\hline & 5 & 4 & 0.01 & 0.30 & 0.12 & 0.13 \\
\hline & 6 & 2 & 0.11 & 0.23 & 0.17 & 0.08 \\
\hline & 7 & 1 & 0.35 & 0.35 & 0.35 & \\
\hline & 8 & 1 & 0.48 & 0.48 & 0.48 & \\
\hline & 9 & 1 & 0.76 & 0.76 & 0.76 & \\
\hline & 10 & 1 & 0.52 & 0.52 & 0.52 & \\
\hline & Mother & 21 & 0.29 & 0.80 & 0.56 & 0.13 \\
\hline
\end{tabular}

Note. Level of responsiveness was calculated as the number of times a sibling or mother responded to a behavior divided by the number of times the infant performed the behavior (i.e., responses/infant behavior).

The MANCOVA was significant and there was a significant effect of age after controlling for the effect of being in the same family (Table 4). Level of responsiveness varied as a function of age and there was a strong relationship between the two variables, as indicated by partial $\eta^{2}$ values for age ranging from .33 to .84 . The effect of family as a covariate was not significantly related to level of responsiveness (all $p>.559$, Table 4 ). 
Table 4. Multivariate Analyses of Covariance for Level of Responsiveness to Infant Behaviors by Age

\begin{tabular}{|c|c|c|c|c|c|c|}
\hline 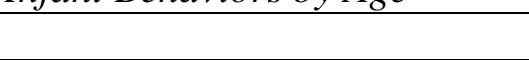 & Source & df & $\mathbf{F}$ & $\mathbf{p}$ & $\eta^{2}$ & Power \\
\hline \multirow{4}{*}{$\begin{array}{l}\text { Infant Object-Related Non-Vocal } \\
\text { Responsiveness }\end{array}$} & Family & 1 & .35 & .559 & .01 & .09 \\
\hline & Age** & 8 & 24.12 & $<.001$ & .84 & 1.00 \\
\hline & Error & 37 & & & & \\
\hline & Total & 46 & & & & \\
\hline \multirow{4}{*}{$\begin{array}{l}\text { Infant Object-Related Vocal } \\
\text { Responsiveness }\end{array}$} & Family & 1 & .07 & .795 & .00 & .06 \\
\hline & Age** & 8 & 12.59 & $<.001$ & .73 & 1.00 \\
\hline & Error & 37 & & & & \\
\hline & Total & 46 & & & & \\
\hline \multirow{4}{*}{$\begin{array}{l}\text { Infant Dyadic Non-Vocal } \\
\text { Responsiveness }\end{array}$} & Family & 1 & .25 & .623 & .01 & .08 \\
\hline & Age* & 8 & 2.27 & .043 & .33 & .80 \\
\hline & Error & 37 & & & & \\
\hline & Total & 46 & & & & \\
\hline \multirow{4}{*}{$\begin{array}{l}\text { Infant Dyadic Vocal } \\
\text { Responsiveness }\end{array}$} & Family & 1 & .00 & 1.00 & .00 & .05 \\
\hline & Age $^{* *}$ & 8 & 4.15 & .001 & .47 & .98 \\
\hline & Error & 37 & & & & \\
\hline & Total & 46 & & & & \\
\hline \multirow{4}{*}{ Overall Responsiveness } & Family & 1 & .03 & .870 & .00 & .05 \\
\hline & Age** & 8 & 21.84 & $<.001$ & .83 & 1.00 \\
\hline & Error & 37 & & & & \\
\hline & Total & 46 & & & & \\
\hline
\end{tabular}

$* * p<.001$

$* p<.05$

Follow-up tests were conducted to evaluate pairwise differences among the adjusted means for age. Bonferonni pairwise comparisons indicated that 3-, 4-, 5-, and 6-year-olds did not differ significantly in their responses to any of the infant behaviors (all $p>.05$ ). Because follow-up tests showed no differences, in subsequent MANCOVAs, the data for children in these age groups were collapsed to create an age group called 3-6 years.

Similarly, older siblings who were 7, 8, 9, and 10 years of age were combined into an older age group called 7-10 years. As is consistent with previous research, few of the mothers had both a 12-month-old infant and a child older than 6 years (see e.g., Wineberg and McCarthy 1989, U.S. Census Bureau 2010, Cancian and Reed 2009). Because the sample size of siblings older than 6 years was small and the level of overall responsiveness for these siblings was similar, the data were combined. Additional MANCOVAs were conducted using combined age groups as the new independent variable. Sample sizes for the combined age groups were: $3-6$ years $n=21,7-10$ years $n=4$, and mothers $n=21$ (see Table 5 for descriptive statistics of infant behaviors, responses, and level of responsiveness by combined age groups). 
Table 5. Descriptive Statistics for Infant Behaviors, Response to Infant Behaviors, and Sibling/Mother Level of Responsiveness by Combined Age Groups

\begin{tabular}{|c|c|c|c|c|c|c|}
\hline & Age & $n$ & Minimum & Maximum & Mean & $\begin{array}{l}\text { Standard } \\
\text { Deviation }\end{array}$ \\
\hline \multirow{3}{*}{$\begin{array}{l}\text { Number of Infant } \\
\text { Behaviors: Infant } \\
\text { Object-Related Non- } \\
\text { Vocal }\end{array}$} & 3-6 Years & 22 & 21 & 910 & 152.14 & 183.97 \\
\hline & 7-10 Years & 4 & 40 & 140 & 99.00 & 42.41 \\
\hline & Mother & 21 & 50 & 637 & 203.86 & 174.56 \\
\hline \multirow{3}{*}{$\begin{array}{l}\text { Number of Times } \\
\text { Sibling/Mother } \\
\text { Responded to Infant } \\
\text { Object-Related Non- } \\
\text { Vocal }\end{array}$} & 3-6 Years & 22 & 0 & 35 & 8.73 & 8.90 \\
\hline & 7-10 Years & 4 & 34 & 56 & 44.50 & 9.57 \\
\hline & Mother & 21 & 24 & 316 & 100.90 & 81.09 \\
\hline \multirow{3}{*}{$\begin{array}{l}\text { Level of } \\
\text { Responsiveness: Infant } \\
\text { Object-Related Non- } \\
\text { Vocal Responsiveness }\end{array}$} & 3-6 Years & 22 & 0.00 & 0.20 & 0.08 & 0.07 \\
\hline & 7-10 Years & 4 & 0.29 & 0.85 & 0.52 & 0.24 \\
\hline & Mother & 21 & 0.25 & 0.76 & 0.53 & 0.13 \\
\hline \multirow{3}{*}{$\begin{array}{l}\text { Number of Infant } \\
\text { Behaviors: Infant } \\
\text { Object-Related Vocal }\end{array}$} & 3-6 Years & 22 & 0 & 109 & 28.23 & 30.88 \\
\hline & 7-10 Years & 4 & 31 & 109 & 58.00 & 35.87 \\
\hline & Mother & 21 & 5 & 215 & 58.10 & 49.12 \\
\hline \multirow{3}{*}{$\begin{array}{l}\text { Number of Times } \\
\text { Sibling/Mother } \\
\text { Responded to Infant } \\
\text { Object-Related Vocal }\end{array}$} & 3-6 Years & 22 & 0 & 13 & 3.23 & 4.17 \\
\hline & 7-10 Years & 4 & 19 & 53 & 32.75 & 14.38 \\
\hline & Mother & 21 & 4 & 81 & 31.95 & 22.42 \\
\hline \multirow{3}{*}{$\begin{array}{l}\text { Level of } \\
\text { Responsiveness: Infant } \\
\text { Object-Related Vocal } \\
\text { Responsiveness }\end{array}$} & 3-6 Years & 22 & 0.00 & 0.38 & 0.10 & 0.12 \\
\hline & 7-10 Years & 4 & 0.49 & 0.86 & 0.62 & 0.17 \\
\hline & Mother & 21 & 0.24 & 0.92 & 0.61 & 0.20 \\
\hline \multirow{3}{*}{$\begin{array}{l}\text { Number of Infant } \\
\text { Behaviors: Infant } \\
\text { Dyadic Non-Vocal }\end{array}$} & 3-6 Years & 22 & 0 & 5 & 0.77 & 1.66 \\
\hline & 7-10 Years & 4 & 0 & 1 & 0.25 & 0.50 \\
\hline & Mother & 21 & 0 & 41 & 6.62 & 11.10 \\
\hline \multirow{3}{*}{$\begin{array}{l}\text { Number of Times } \\
\text { Sibling/Mother } \\
\text { Responded to Infant } \\
\text { Dyadic Non-Vocal }\end{array}$} & 3-6 Years & 22 & 0 & 3 & 0.41 & 0.91 \\
\hline & 7-10 Years & 4 & 0 & 1 & 0.25 & 0.50 \\
\hline & Mother & 21 & 0 & 33 & 4.71 & 8.43 \\
\hline \multirow{3}{*}{$\begin{array}{l}\text { Level of } \\
\text { Responsiveness: Infant } \\
\text { Dyadic Non-Vocal } \\
\text { Responsiveness } \\
\end{array}$} & 3-6 Years & 22 & 0.00 & 1.00 & 0.13 & 0.28 \\
\hline & 7-10 Years & 4 & 0.00 & 1.00 & 0.25 & 0.50 \\
\hline & Mother & 21 & 0.00 & 1.00 & 0.44 & 0.41 \\
\hline \multirow{3}{*}{$\begin{array}{l}\text { Number of Infant } \\
\text { Behaviors: Infant } \\
\text { Dyadic Vocal }\end{array}$} & 3-6 Years & 22 & 0 & 44 & 3.05 & 9.49 \\
\hline & 7-10 Years & 4 & 0 & 103 & 26.00 & 51.34 \\
\hline & Mother & 21 & 0 & 136 & 15.62 & 30.37 \\
\hline \multirow{3}{*}{$\begin{array}{l}\text { Number of Times } \\
\text { Sibling/Mother } \\
\text { Responded to Infant } \\
\text { Dyadic Vocal }\end{array}$} & 3-6 Years & 22 & 0 & 21 & 1.27 & 4.54 \\
\hline & 7-10 Years & 4 & 0 & 71 & 18.00 & 35.34 \\
\hline & Mother & 21 & 0 & 94 & 11.48 & 21.26 \\
\hline \multirow{2}{*}{$\begin{array}{l}\text { Level of } \\
\text { Responsiveness: Infant }\end{array}$} & 3-6 Years & 22 & 0.00 & 0.50 & 0.08 & 0.18 \\
\hline & 7-10 Years & 4 & 0.00 & 1.00 & 0.42 & 0.50 \\
\hline
\end{tabular}




\begin{tabular}{|c|c|c|c|c|c|c|}
\hline & Age & $n$ & Minimum & Maximum & Mean & $\begin{array}{l}\text { Standard } \\
\text { Deviation }\end{array}$ \\
\hline $\begin{array}{l}\text { Dyadic Vocal } \\
\text { Responsiveness }\end{array}$ & Mother & 21 & 0.00 & 1.00 & 0.55 & 0.40 \\
\hline \multirow{3}{*}{$\begin{array}{l}\text { Level of } \\
\text { Responsiveness: } \\
\text { Overall } \\
\text { Responsiveness }\end{array}$} & 3-6 Years & 22 & 0.00 & 0.30 & 0.09 & 0.08 \\
\hline & 7-10 Years & 4 & 0.35 & 0.76 & 0.53 & 0.17 \\
\hline & Mother & 21 & 0.29 & 0.80 & 0.56 & 0.13 \\
\hline
\end{tabular}

Note. Level of responsiveness was calculated as the number of times a sibling or mother responded to a behavior divided by the number of times the infant performed the behavior (i.e., responses/infant behavior).

Table 6. Multivariate Analysis of Covariance for Level of Responsiveness to Infant Behaviors by Combined Age Groups

\begin{tabular}{|c|c|c|c|c|c|c|}
\hline & & df & $\mathbf{F}$ & $\mathbf{p}$ & $\eta^{2}$ & Power \\
\hline \multirow{4}{*}{$\begin{array}{l}\text { Infant Object-Related Non-Vocal } \\
\text { Responsiveness }\end{array}$} & Family & 1 & .19 & .668 & .00 & .07 \\
\hline & Age** & 2 & 72.94 & $<.001$ & .77 & 1.00 \\
\hline & Error & 43 & & & & \\
\hline & Total & 46 & & & & \\
\hline \multirow{4}{*}{$\begin{array}{l}\text { Infant Object-Related Vocal } \\
\text { Responsiveness }\end{array}$} & Family & 1 & .05 & .822 & .00 & .06 \\
\hline & $\operatorname{Age}^{* *}$ & 2 & 47.54 & $<.001$ & .69 & 1.00 \\
\hline & Error & 43 & & & & \\
\hline & Total & 46 & & & & \\
\hline \multirow{4}{*}{$\begin{array}{l}\text { Infant Dyadic Non-Vocal } \\
\text { Responsiveness }\end{array}$} & Family & 1 & .03 & .87 & .00 & .05 \\
\hline & Age* $^{*}$ & 2 & 3.69 & .033 & .15 & .65 \\
\hline & Error & 43 & & & & \\
\hline & Total & 46 & & & & \\
\hline \multirow{4}{*}{ Infant Dyadic Vocal Responsiveness } & Family & 1 & .21 & 649 & .00 & .07 \\
\hline & Age** & 2 & 11.06 & $<.001$ & .34 & .99 \\
\hline & Error & 43 & & & & \\
\hline & Total & 46 & & & & \\
\hline \multirow{4}{*}{ Overall Responsiveness } & Family & 1 & .05 & .830 & .00 & .06 \\
\hline & Age** & 2 & 78.48 & $<.001$ & .78 & 1.00 \\
\hline & Error & 43 & & & & \\
\hline & Total & 46 & & & & \\
\hline
\end{tabular}

$* * p<.001$

In analyses with combined age groups, controlling for participants being in the same family, there was a significant effect of age with partial $\eta^{2}$ values ranging from .15 to .78 (Table 6). The effect of family was not significantly related to level of responsiveness for any of the variables (all $p>.649$, Table 6). Planned Bonferonni pairwise comparisons revealed that there were significant differences in sibling and mother level of responsiveness to all infant behaviors (Table 7). There were also significant differences in levels of responsiveness between the 3-6 and 7-10 age groups. Overall, siblings in the 7-10 age group were more responsive than siblings in the 3-6 age group (3-6 years age group level of responsiveness mean range: .08-.13, 7-10 years age group level of responsiveness mean range: .25-.62; Table 7, Figure 1, Figure 2, Figure 3). 
Table 7. Bonferroni Pairwise Comparisons of Level of Responsiveness for Combined Age Groups

\begin{tabular}{|c|c|c|c|c|c|}
\hline & & & \multicolumn{3}{|c|}{ p-values } \\
\hline & Age Group & Mean & 3-6 Years & 7-10 Years & Mother \\
\hline \multirow{3}{*}{$\begin{array}{l}\text { Infant Object-Related } \\
\text { Non-Vocal } \\
\text { Responsiveness }\end{array}$} & 3-6 Years & 0.08 & - & $<.001 * *$ & $<.001 * *$ \\
\hline & 7-10 Years & 0.52 & $<.001 * *$ & - & 1 \\
\hline & Mother & 0.53 & $<.001 * *$ & 1 & - \\
\hline \multirow{3}{*}{$\begin{array}{l}\text { Infant Object-Related } \\
\text { Vocal Responsiveness }\end{array}$} & 3-6 Years & 0.10 & - & $<.001 * *$ & $<.001 * *$ \\
\hline & 7-10 Years & 0.62 & $<.001 * *$ & - & 1 \\
\hline & Mother & 0.61 & $<.001 * *$ & 1 & - \\
\hline \multirow{3}{*}{$\begin{array}{l}\text { Infant Dyadic Non-Vocal } \\
\text { Responsiveness }\end{array}$} & 3-6 Years & 0.13 & - & 1 & $.036 *$ \\
\hline & 7-10 Years & 0.25 & 1 & - & 1 \\
\hline & Mother & 0.44 & $.036 *$ & 1 & - \\
\hline \multirow{3}{*}{$\begin{array}{l}\text { Infant Dyadic Vocal } \\
\text { Responsiveness }\end{array}$} & 3-6 Years & 0.08 & - & .292 & $<.001 * *$ \\
\hline & 7-10 Years & 0.42 & .292 & - & 1 \\
\hline & Mother & 0.55 & $<.001 * *$ & 1 & - \\
\hline \multirow{3}{*}{ Overall Responsiveness } & 3-6 Years & 0.09 & - & $<.001 * *$ & $<.001 * *$ \\
\hline & 7-10 Years & 0.53 & $<.001 * *$ & - & 1 \\
\hline & Mother & 0.56 & $<.001 * *$ & 1 & - \\
\hline
\end{tabular}

$* * p<.001$

$* p<.05$

Mothers' level of responsiveness to all infant behaviors was significantly different from children in the 3-6 years age group. When compared to 3- to 6year-olds, mothers were more responsive to infant object-related non-vocal, object-related vocal, dyadic non-vocal, and dyadic vocal behaviors (all $p<$ .036). In terms of overall responsiveness level, mothers responded to $56 \%$ of infant behaviors while 3- to 6-year-olds responded to $10 \%$ of infant behaviors ( $p<.001$; for pairwise comparisons and responsiveness levels see Table 7, Figure 1, Figure 2, Figure 3).

Figure 1. Mean Level of responsiveness to Infant Object-related behaviors by combined Age Group

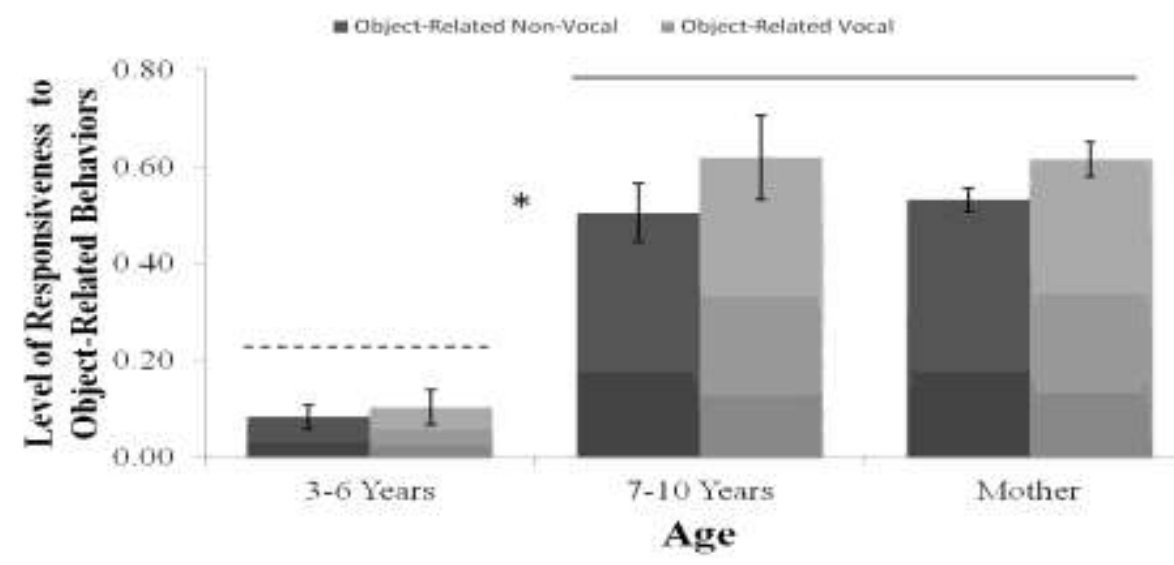


Mothers and Older Siblings in the 7-10 Years Age Group did not differ significantly in Level of responsiveness to Object-related behaviors. Mothers and 7- to 10-year-olds differed significantly from 3- to 6-year-olds. Significant differences are denoted by an asterisk (*). Error bars represent standard errors

Figure 2. Mean Level of responsiveness to Infant Dyadic behaviors by combined Age Group.

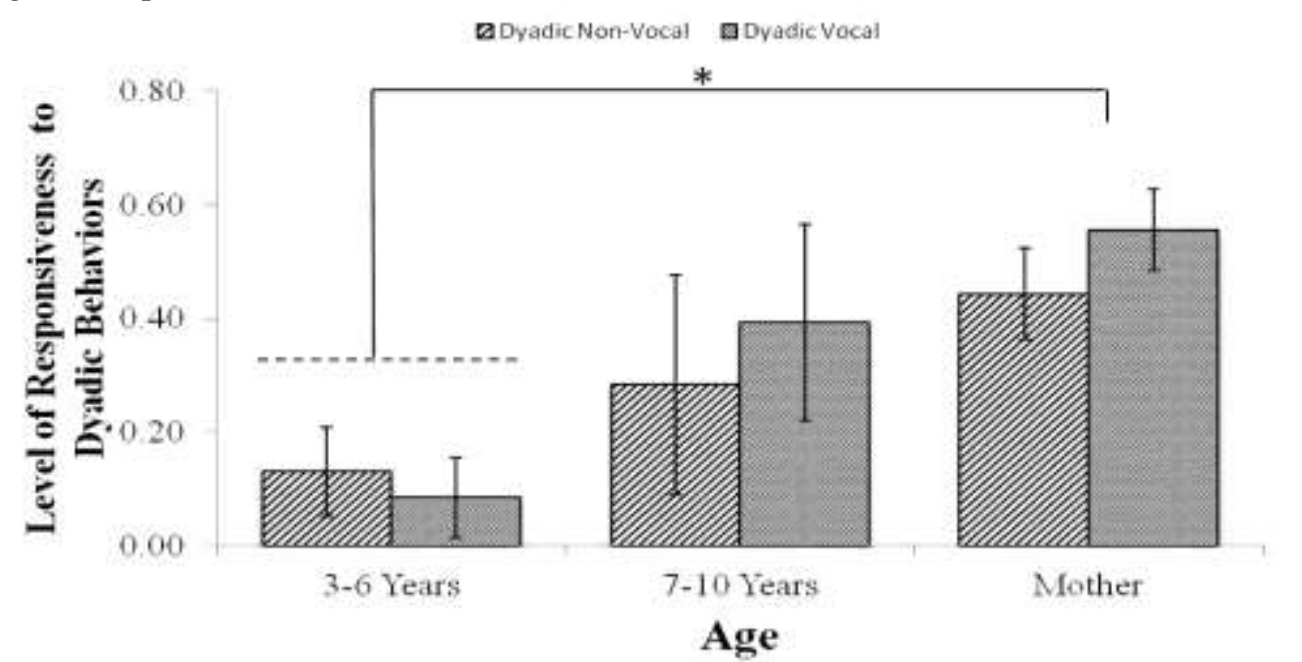

Older Siblings in the 7-10 years age group did not differ significantly from 3- to 6-year-olds in level of responsiveness to infant dyadic behaviors. 7- to 10year-olds also did not differ significantly from mothers. Mothers had a higher responsiveness level than 3- to 6-year-olds and differed significantly from the 3-6 years age group. Significant differences are denoted by an asterisk (*). Error bars represent standard errors

Figure 3. Mean Overall Level of Responsiveness to Infant behaviors by combined Age Group.

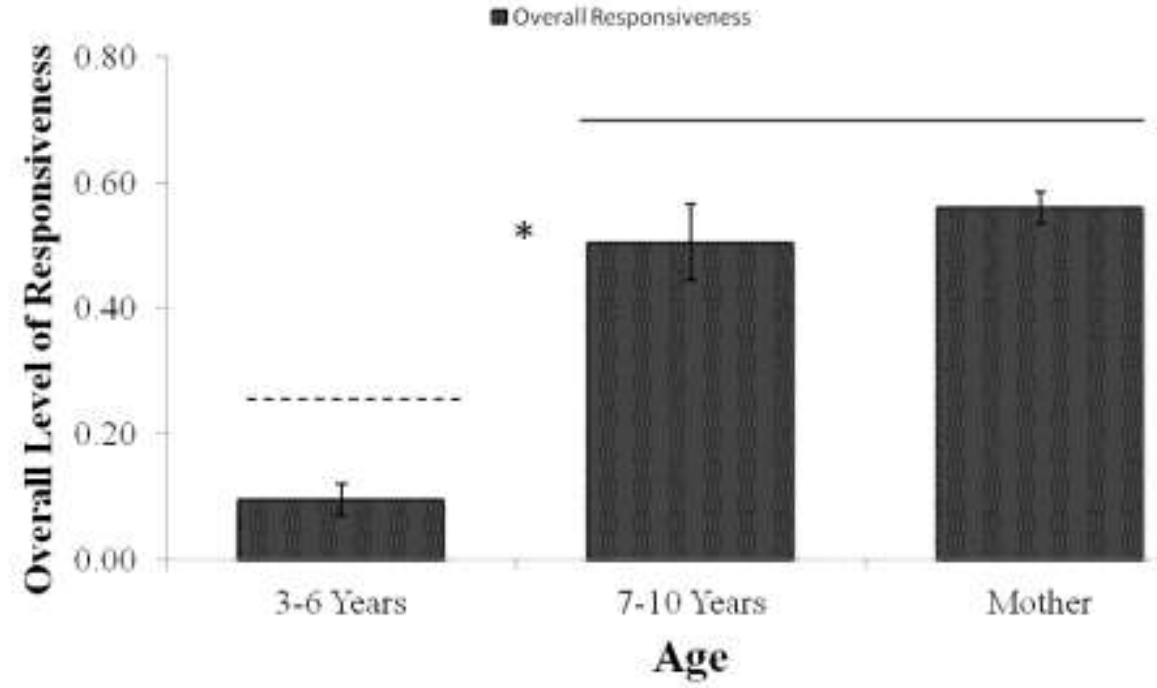


Mothers and older Siblings in the 7-10 Years Age Group did not differ significantly in Overall Level of Responsiveness. Mothers and 7- to 10-yearolds differed significantly from 3- to 6-year-olds. Significant differences are denoted by an asterisk $(*)$. Error bars represent standard errors.

In contrast, mothers' level of responsiveness to infant behaviors was not significantly different from siblings in the 7-10 years age group. Mothers and siblings aged 7 to 10 years had the same level of responsiveness to infant object-related non-vocal, object-related vocal, dyadic non-vocal, and dyadic vocal behaviors (all $p=1$ ). For overall responsiveness, mothers responded to $56 \%$ of infant behaviors and 7- to 10 -year-olds responded to $50 \%$ of infant behaviors ( $p=1$; Table 7, Figure 1, Figure 2, Figure 3$)$. The results indicate that 7- to 10-year-old siblings' level of responsiveness to infant behaviors is similar to their mothers' level of responsiveness. This pattern is based on a small sample size and emerged as a result of the similarities between the levels of responsiveness displayed by the four siblings in the 7-10 age group.

Comparisons of the two sibling age groups revealed that the 7-10 years age group differed from the 3-6 years age group in their level of responsiveness to infant object-related behaviors (object non-vocal and object-related vocal behaviors, $p<.001$; Table 7 , Figure 1$)$ and overall responsiveness $(p<.001$; Figure 3). Level of responsiveness was not different for dyadic behaviors (dyadic non-vocal $p=1$ and dyadic vocal $p=.292$; Table 7, Figure 2). Age differences in level of responsiveness to object-related and dyadic behaviors indicate that older siblings may respond selectively to certain behaviors. In particular, siblings in the 7-10 years age group were more likely to respond to object-related behaviors than dyadic behaviors, indicating that although 7- to 10-year-old siblings' level of responsiveness was similar to their mothers', siblings in this age group did not respond exactly like their mothers. Differences in dyadic responsiveness may be attributed to the fact that infants did not emit any dyadic behaviors during play sessions with their 7- and 8-year- old siblings. Thus, although 7 and 8 year olds responded to the infants' behaviors, they were never given the opportunity to respond to infant dyadic behaviors because the infants did not display dyadic behaviors during those play sessions (see Table $3)$.

It is important to note that pattern of responsiveness for 7- to 10-year-old siblings cannot be attributed to one child in the 7-10 age group. For example, although the 9-year-old exhibited high levels of object-related responsiveness and the 10-year-old exhibited high levels of dyadic responsiveness, excluding the data for either one or both of these participants did not significantly affect the results of the group comparisons. When one participant was excluded, siblings in the older age group were not significantly different from mothers in their levels of responsiveness to object-related non-vocal behaviors, objectrelated vocal behaviors, dyadic non-vocal behaviors, dyadic behaviors, or overall level of responsiveness (all $p>.05$ ). Similarly, when both participants were excluded from the analyses, siblings in the older age group were not significantly different from mothers in their levels of responsiveness to any of the infant behaviors (all $p>.05)$. 
An independent-samples t-test was conducted to compare the level of responsiveness of male and female older siblings. Males $(n=12)$ and females $(n=10)$ in the 3-6 years age group differed in their level of responsiveness to infant object-related non-vocal behavior, $t(20)=2.54, p=.02$, but not to any other behavior (all $p>.07)$. Males $(n=1)$ and females $(n=3)$ in the 7-10 years age group did not differ in their level of responsiveness to any of the infant behaviors (all $p>.05$ ). However, given that gender role expectations and gender intensification increase during early adolescence (see e.g., Galambos et al. 1990, Crouter et al. 1995), a larger sample size of 7- to 10-year-old siblings may yield different results.

\section{Additional Influences on Level of Responsiveness}

Pearson product-moment correlation coefficients were computed to assess the relationship between siblings' overall responsiveness and other mother or sibling factors. For the following analyses, sibling age was used rather than age group. Mother work status (i.e., inside or outside the home, $r=.42, n=26, p=$ $.03)$, hours per week that older siblings spent at school $(r=.64, n=26, p<$ .001 ), number of times per week that the older sibling "read" books (i.e., reading was loosely defined as the older sibling using a book to tell the infant a story by either looking at the pictures or reading the words) to the infant ( $r=$ $.54, n=26, p=.005$ ), and hours per week that the older sibling was required to babysit the infant $(r=.891, n=26, p<.01)$ were significantly positively correlated with overall responsiveness. Total hours per week that the older sibling spent with the infant ( $r=-.194, n=26, p=.34$ ) was not significantly correlated with overall responsiveness. Given the strong correlations between level of responsiveness and the abovementioned factors, multiple regressions were conducted to assess which factors were the best predictors of level of responsiveness to each infant behavior (i.e., levels of responsiveness to infant object-related and dyadic behaviors were included as dependent outcomes). Backward stepwise regressions was conducted in which all factors were included in the initial model and then each non-significant factor was removed until the best, and final, model emerged. 
Table 8. Linear Regressions for Responsiveness to Infant Behaviors

\begin{tabular}{|c|c|c|c|c|c|c|}
\hline Behavior & Variable & B & $\begin{array}{c}\text { Standard } \\
\text { Error }\end{array}$ & Beta & p & $\begin{array}{c}\text { Adjusted } \\
\mathbf{R}^{2} \\
\end{array}$ \\
\hline & Constant & 0.072 & 0.016 & & $<.001$ & 0.86 \\
\hline Object-Related Non-Vocal Responsiveness & $\begin{array}{c}\text { Hours/ } \\
\text { Week Older } \\
\text { Sibling } \\
\text { Required to } \\
\text { Babysit } \\
\text { Infant } \\
\end{array}$ & 0.069 & 0.006 & $0.929 * *$ & $<.001$ & \\
\hline \multirow{3}{*}{ Object-Related Vocal Responsiveness } & Constant & 0.203 & 0.055 & & $<.001$ & 0.76 \\
\hline & $\begin{array}{l}\text { Hours/Week } \\
\text { Older } \\
\text { Sibling } \\
\text { Required to } \\
\text { Babysit } \\
\text { Infant } \\
\end{array}$ & 0.071 & 0.009 & $0.818 * *$ & $<.001$ & \\
\hline & $\begin{array}{l}\text { Hours/Week } \\
\text { Older } \\
\text { Sibling } \\
\text { Spends with } \\
\text { Infant }\end{array}$ & -0.001 & 0.0004 & $-0.211^{*}$ & .046 & \\
\hline \multirow[b]{3}{*}{ Dyadic Non-Vocal Responsiveness } & Constant & -0.527 & 0.185 & & .009 & 0.34 \\
\hline & Age & 0.170 & 0.044 & $1.065^{*}$ & .001 & \\
\hline & $\begin{array}{l}\text { Hours/Week } \\
\text { Older } \\
\text { Sibling } \\
\text { Required to } \\
\text { Babysit } \\
\text { Infant }\end{array}$ & -0.100 & 0.034 & $-0.827 *$ & .007 & \\
\hline \multirow{2}{*}{ Dyadic Vocal Responsiveness } & Constant & -0.263 & 0.111 & & .026 & 0.36 \\
\hline & Age & 0.085 & 0.022 & $0.619 *$ & .001 & \\
\hline \multirow[b]{3}{*}{ Overall Responsiveness } & Constant & -0.053 & 0.056 & & .351 & 0.83 \\
\hline & Age & 0.036 & 0.013 & $0.377^{*}$ & .014 & \\
\hline & $\begin{array}{l}\text { Hours/Week } \\
\text { Older } \\
\text { Sibling } \\
\text { Required to } \\
\text { Babysit } \\
\text { Infant }\end{array}$ & 0.042 & 0.010 & $0.585 * *$ & $<.001$ & \\
\hline
\end{tabular}

The best predictors of level of responsiveness were sibling age and hours per week that the older sibling was required to babysit the infant. Although siblings in the 7-10 age group $(M=6.5$ hours per week, $S D=3)$ were required to babysit more than siblings in the 3-6 age group $(M=.13$ hours per week, $S D$ $=.28$ ), there were five younger siblings (ages $3[n=1], 4[n=1], 5[n=2]$, and $6[n=1] ; M=.55$ hours per week, $S D=.33$ ) who had regular babysitting responsibilities. Results of the object-related non-vocal regression indicated that hours spent babysitting explained $86 \%$ of the variance $(F(1,24)=150.55$, $p<.001$; Table 8). Hours per week spent babysitting and hours per week that the older sibling spent with the infant $\left(R^{2}=.76, F(2,23)=39.67, p<.001\right.$; Table 8) were the best predictors of responsiveness to object-related vocal behavior. Responsiveness to dyadic non-vocal behavior was best predicted by age and hours spent babysitting $\left(R^{2}=.34, F(2,23)=7.31, p=.003\right.$; Table 8$)$ 
while responsiveness to dyadic vocal behavior was best predicted by age alone $\left(R^{2}=.36, F(1,24)=14.95, p=.001\right.$; Table 8$)$. Siblings' overall level of responsiveness was best predicted by age and hours spent babysitting $(F(2,23)$ $=61.48, p<.001$; Table 8$)$; these two predictors explained $83 \%$ of the variance in overall level of responsiveness. Thus, in addition to age, the amount of time that siblings were required to take on the responsibilities of a caregiver resulted in increased levels of responsiveness to infant behavior.

\section{Sequential Data Analysis}

To assess social learning of caregiving behavior, older siblings' responsiveness behaviors were compared to their mothers using sequential data analysis (see e.g., Bobbitt et al. 1969, Fisher and Sanderson 1996, Hofmann et al. 1999, Jeong 2005, Kogan and Wimberger 1966, Lii 1981, Olson et al. 1994, Pan 2010, Sawin et al. 1977, Sigel and Parke 1987, the behavioral coding procedure did not change and was the same as the coding procedure described above in the Method section). Sequential analyses were used to identify recurring behavioral patterns. For example, after an infant emitted a dyadic vocalization, with which behavior (e.g., dyadic non-vocalization, dyadic vocalization) were mothers most likely to respond? Was the probability of responding with one type of behavior greater than the probability of responding with another type of behavior? Were older siblings' responsive behavioral patterns the same as their mothers' patterns? Sequential analyses allowed us to examine these questions and determine which behavioral sequences occurred at rates that were significantly greater than chance. For the following analyses, a behavioral sequence consisted of two behaviors - an initial behavior and the behavior immediately following it (i.e., lag 1 analysis).

Lag 1 sequential analyses were conducted using repeating consecutive behaviors (Bakeman and Quera 1995). For repeating consecutive analyses, all infant, sibling, and mother behaviors were examined. Consecutive behaviors provided a more detailed measure of how the infant and mother/sibling interacted during the 20-minute play session. In these analyses, we were also interested in how infants responded to mother/sibling-initiated behaviors. Hence, the analysis was bi-directional and the first behavior in a behavioral sequence could be either an infant-initiated or a mother/sibling-initiated behavior. For a repeating consecutive behavior analysis, a behavioral sequence of infant dyadic vocal (idv), infant dyadic vocal (idv), sibling dyadic vocal (sdv), infant object-related non-vocal (ion) would result in an idv to idv frequency of 1 and a transitional probability of .50, an idv to sdv frequency of 1 and a transitional probability of 1 , and an idv to ion frequency of 0 and a transitional probability of 0 . Sequential data analysis comparisons were performed using O'Connor's (1999) SEQGROUPS SPSS syntax program. 


\section{Sibling and Mother Sequential Data Comparisons}

Repeating consecutive behaviors allowed us to more closely examine the frequency and transitional probability from infant behavior to sibling or mother behavior. Thus, we could compare the individual response patterns of older siblings to those of their mothers. The repeating analysis also provided a bidirectional measure of how participants were responding to each other during the play sessions. It allowed us to examine which behaviors siblings and mothers were most likely to respond to as well as which sibling and mother behaviors infants were likely to respond to. In particular, we looked at behavioral patterns and examined whether certain behaviors were more likely to follow others.

Individual sequential analyses were performed for every triad. For each triad, sibling-mother comparisons based on likelihood ratio chi-square tests revealed that there were significant differences in the behavioral patterns of infant-sibling interactions compared to infant-mother interactions (Likelihood Ratio Chi-Square ranged from $\chi^{2}=204.57$ to $\chi^{2}=1262.41, d f=132, p<.001$ ). To compare the transitional probabilities of initial behaviors and following behaviors in infant-sibling and infant-mother interactions, the data for all sibling interactions were combined and compared to the combined data for all mother interactions.

The behaviors most likely to follow infant object-related behaviors, infant cries, and other infant vocal behaviors differed most for the two types of interactions. During infant-sibling interactions, infant object-related non-vocal and infant object-related vocal behaviors were most often not responded to and siblings engaged in other vocal and non-vocal behaviors (i.e., soo and sot) that were not related to the object the infant was focused on (Table 9). Similarly, siblings were not likely to respond when infants cried or when infants engaged in non-dyadic vocal behaviors. Siblings, however, did respond to infant dyadic behaviors. Approximately $50 \%$ of infant dyadic vocal behaviors were followed by sibling dyadic vocal behaviors.

Mothers were most likely to respond to infant behaviors with dyadic vocalizations (Table 10). With the exception of infant object-related non-vocal behaviors, which were most likely followed by infant object related non-vocal behaviors, mothers tended to provide vocal responses to infant behaviors. Even when infants were crying, mothers responded with either other vocal behaviors or dyadic vocal behaviors. 
Table 9. Repeating Analysis: Infant-sibling Interaction

\begin{tabular}{|c|c|c|c|c|c|c|c|c|c|c|c|c|c|}
\hline \multicolumn{14}{|c|}{ Frequencies } \\
\hline & ion & iov & idn & $\mathrm{idv}$ & icry & iot & son & sov & sdn & $\mathrm{sdv}$ & sot & soo & Total \\
\hline ion & 654 & 112 & 2 & 3 & 8 & 54 & 85 & 87 & 17 & 170 & 693 & 739 & 2624 \\
\hline iov & 74 & 181 & 0 & 0 & 4 & 6 & 40 & 53 & 2 & 108 & 210 & 117 & 795 \\
\hline idn & 0 & 1 & 1 & 1 & 0 & 1 & 0 & 0 & 4 & 5 & 3 & 1 & 17 \\
\hline $\mathrm{idv}$ & 5 & 2 & 1 & 33 & 1 & 1 & 10 & 4 & 6 & 82 & 19 & 1 & 165 \\
\hline icry & 17 & 4 & 0 & 0 & 88 & 3 & 4 & 1 & 11 & 12 & 46 & 63 & 249 \\
\hline iot & 41 & 3 & 0 & 2 & 21 & 174 & 13 & 4 & 14 & 47 & 178 & 162 & 659 \\
\hline son & 110 & 46 & 1 & 11 & 5 & 16 & 168 & 57 & 2 & 20 & 52 & 25 & 513 \\
\hline sov & 103 & 43 & 2 & 2 & 0 & 6 & 53 & 223 & 2 & 26 & 29 & 23 & 512 \\
\hline sdn & 18 & 5 & 6 & 9 & 11 & 18 & 3 & 2 & 42 & 26 & 21 & 7 & 168 \\
\hline $\mathrm{sdv}$ & 154 & 83 & 1 & 94 & 11 & 41 & 38 & 28 & 37 & 353 & 55 & 86 & 981 \\
\hline sot & 701 & 193 & 2 & 10 & 41 & 180 & 50 & 28 & 22 & 55 & 1300 & 934 & 3516 \\
\hline soo & 747 & 121 & 1 & 1 & 58 & 158 & 49 & 25 & 9 & 76 & 915 & 1496 & 3656 \\
\hline Total & 2624 & 794 & 17 & 166 & 248 & 658 & 513 & 512 & 168 & 980 & 3521 & 3654 & 13855 \\
\hline \multicolumn{14}{|c|}{ Transitional Probabilities* } \\
\hline & ion & iov & idn & idv & icry & iot & son & sov & $\operatorname{sdn}$ & $\mathrm{sdv}$ & sot & soo & \\
\hline ion & 0.249 & 0.043 & 0.001 & 0.001 & 0.003 & 0.021 & 0.032 & 0.033 & 0.007 & 0.065 & 0.264 & 0.282 & \\
\hline iov & 0.093 & 0.228 & 0.000 & 0.000 & 0.005 & 0.008 & 0.050 & 0.067 & 0.003 & 0.136 & 0.264 & 0.147 & \\
\hline idn & 0.000 & 0.059 & 0.059 & 0.059 & 0.000 & 0.059 & 0.000 & 0.000 & 0.235 & 0.294 & 0.177 & 0.059 & \\
\hline $\mathrm{idv}$ & 0.030 & 0.012 & 0.006 & 0.200 & 0.006 & 0.006 & 0.061 & 0.024 & 0.036 & 0.497 & 0.115 & 0.006 & \\
\hline icry & 0.068 & 0.016 & 0.000 & 0.000 & 0.353 & 0.012 & 0.016 & 0.004 & 0.044 & 0.048 & 0.185 & 0.253 & \\
\hline iot & 0.062 & 0.005 & 0.000 & 0.003 & 0.032 & 0.264 & 0.020 & 0.006 & 0.021 & 0.071 & 0.270 & 0.246 & \\
\hline son & 0.214 & 0.090 & 0.002 & 0.021 & 0.010 & 0.031 & 0.328 & 0.111 & 0.004 & 0.039 & 0.101 & 0.049 & \\
\hline sov & 0.201 & 0.084 & 0.004 & 0.004 & 0.000 & 0.012 & 0.104 & 0.436 & 0.004 & 0.051 & 0.057 & 0.045 & \\
\hline sdn & 0.107 & 0.030 & & 0.054 & 0.066 & 0.107 & 0.018 & 0.012 & 0.250 & 0.155 & 0.125 & 0.042 & \\
\hline sdv & 0.157 & 0.085 & 0.001 & 0.096 & 0.011 & 0.042 & 0.039 & 0.029 & 0.038 & 0.360 & 0.056 & 0.088 & \\
\hline sot & 0.199 & 0.055 & 0.001 & 0.003 & 0.012 & 0.051 & 0.014 & 0.008 & 0.006 & 0.016 & 0.370 & 0.266 & \\
\hline soo & 0.204 & 0.033 & 0.000 & 0.000 & 0.016 & 0.043 & 0.013 & 0.007 & 0.003 & 0.021 & 0.250 & 0.409 & \\
\hline \multicolumn{14}{|c|}{ *behavior with the largest transitional probability denoted in bold } \\
\hline \multicolumn{14}{|c|}{ Behavior Category Abbreviations } \\
\hline \multicolumn{6}{|c|}{ ion infant object-related non-vocal } & \multicolumn{8}{|c|}{ son sibling object-related non-vocal } \\
\hline \multicolumn{6}{|c|}{ iov infant object-related vocal } & \multicolumn{8}{|c|}{ sov sibling object-related vocal } \\
\hline \multicolumn{6}{|c|}{ idn infant dyadic non-vocal } & \multicolumn{8}{|c|}{ sdn $\quad$ sibling dyadic non-vocal } \\
\hline \multicolumn{6}{|c|}{ idv infant dyadic vocal } & \multicolumn{8}{|c|}{ sdv sibling dyadic vocal } \\
\hline \multicolumn{6}{|c|}{ icry infant cry } & \multicolumn{8}{|c|}{ sot sibling other vocal } \\
\hline \multicolumn{14}{|c|}{ iot infant other vocal } \\
\hline
\end{tabular}


Table 10. Repeating Analysis: Infant-mother Interaction

\begin{tabular}{|c|c|c|c|c|c|c|c|c|c|c|c|c|c|}
\hline \multicolumn{14}{|c|}{ Frequencies } \\
\hline & ion & iov & idn & idv & icry & iot & mon & mov & mdn & $\mathrm{mdv}$ & mot & moo & Total \\
\hline ion & 1260 & 334 & 14 & 20 & 0 & 17 & 404 & 880 & 67 & 525 & 73 & 182 & 3776 \\
\hline iov & 167 & 247 & 3 & 7 & 0 & 8 & 82 & 294 & 4 & 297 & 46 & 33 & 1188 \\
\hline idn & 5 & 0 & 13 & 9 & 0 & 3 & 11 & 2 & 31 & 36 & 0 & 1 & 111 \\
\hline idv & 6 & 21 & 3 & 39 & 0 & 8 & 9 & 12 & 30 & 220 & 7 & 1 & 356 \\
\hline icry & 0 & 0 & 0 & 0 & 7 & 0 & 0 & 2 & 1 & 6 & 8 & 0 & 24 \\
\hline iot & 18 & 7 & 4 & 5 & 3 & 72 & 10 & 19 & 12 & 89 & 49 & 30 & 318 \\
\hline mon & 447 & 80 & 5 & 8 & 0 & 13 & 322 & 306 & 17 & 69 & 26 & 15 & 1308 \\
\hline mov & 1005 & 236 & 6 & 16 & 3 & 30 & 305 & 1148 & 13 & 101 & 58 & 56 & 2977 \\
\hline mdn & 64 & 10 & 13 & 22 & 1 & 14 & 22 & 11 & 50 & 101 & 5 & 1 & 314 \\
\hline $\mathrm{mdv}$ & 562 & 190 & 46 & 217 & 5 & 78 & 97 & 164 & 78 & 795 & 31 & 61 & 2324 \\
\hline mot & 64 & 42 & 3 & 10 & 2 & 51 & 25 & 62 & 8 & 39 & 220 & 89 & 615 \\
\hline moo & 176 & 23 & 1 & 2 & 3 & 25 & 21 & 79 & 2 & 47 & 93 & 183 & 655 \\
\hline Total & 3774 & 1190 & 111 & 355 & 24 & 319 & 1308 & 2979 & 313 & 2325 & 616 & 652 & 13966 \\
\hline \multicolumn{14}{|c|}{ Transitional Probabilities* } \\
\hline & ion & iov & idn & idv & icry & iot & mon & mov & mdn & $\mathrm{mdv}$ & mot & moo & \\
\hline ion & 0.334 & 0.089 & 0.004 & 0.005 & 0.000 & 0.005 & 0.107 & 0.233 & 0.018 & 0.139 & 0.019 & 0.048 & \\
\hline iov & 0.141 & 0.208 & 0.003 & 0.006 & 0.000 & 0.007 & 0.069 & 0.248 & 0.003 & 0.250 & 0.039 & 0.028 & \\
\hline idn & 0.045 & 0.000 & 0.117 & 0.081 & 0.000 & 0.027 & 0.099 & 0.018 & 0.279 & 0.324 & 0.000 & 0.009 & \\
\hline idv & 0.017 & 0.059 & 0.008 & 0.110 & 0.000 & 0.023 & 0.025 & 0.034 & 0.084 & 0.618 & 0.020 & 0.003 & \\
\hline icry & 0.000 & 0.000 & 0.000 & 0.000 & 0.292 & 0.000 & 0.000 & 0.083 & 0.042 & 0.250 & $\mathbf{0 . 3 3 3}$ & 0.000 & \\
\hline iot & 0.057 & 0.022 & 0.013 & 0.016 & 0.009 & 0.226 & 0.031 & 0.060 & 0.038 & 0.280 & 0.154 & 0.094 & \\
\hline mon & 0.342 & 0.061 & 0.004 & 0.006 & 0.000 & 0.010 & 0.246 & 0.234 & 0.013 & 0.053 & 0.020 & 0.012 & \\
\hline mov & 0.338 & 0.079 & 0.002 & 0.005 & 0.001 & 0.010 & 0.103 & 0.386 & 0.004 & 0.034 & 0.020 & 0.019 & \\
\hline mdn & 0.204 & 0.032 & 0.041 & 0.070 & 0.003 & 0.045 & 0.070 & 0.035 & 0.159 & $\mathbf{0 . 3 2 2}$ & 0.016 & 0.003 & \\
\hline $\mathrm{mdv}$ & 0.242 & 0.082 & 0.020 & 0.093 & 0.002 & 0.034 & 0.042 & 0.071 & 0.034 & 0.342 & 0.013 & 0.026 & \\
\hline mot & 0.104 & 0.068 & 0.005 & 0.016 & 0.003 & 0.083 & 0.041 & 0.101 & 0.013 & 0.063 & 0.358 & 0.145 & \\
\hline moo & 0.269 & 0.035 & 0.002 & 0.003 & 0.005 & 0.038 & 0.032 & 0.121 & 0.003 & 0.072 & 0.142 & 0.279 & \\
\hline \multicolumn{14}{|c|}{ *behavior with the largest transitional probability denoted in bold } \\
\hline \multicolumn{14}{|c|}{ Behavior Category Abbreviations } \\
\hline \multicolumn{6}{|c|}{ ion infant object-related non-vocal } & \multicolumn{8}{|c|}{ mon mother object-related non-vocal } \\
\hline \multicolumn{6}{|c|}{ iov infant object-related vocal } & mov & \multicolumn{7}{|c|}{ mother object-related vocal } \\
\hline \multicolumn{6}{|c|}{ idn infant dyadic non-vocal } & mdn & \multicolumn{7}{|c|}{ mother dyadic non-vocal } \\
\hline \multicolumn{6}{|c|}{ idv infant dyadic vocal } & mdv & \multicolumn{7}{|c|}{ mother dyadic vocal } \\
\hline \multicolumn{6}{|c|}{ icry infant cry } & mot & \multicolumn{7}{|c|}{ mother other vocal } \\
\hline \multicolumn{6}{|c|}{ iot infant other vocal } & moo & \multicolumn{7}{|c|}{ mother other non-vocal } \\
\hline
\end{tabular}

Infants were more likely to respond to both sibling and mother behaviors with infant object-related non-vocal behaviors. It is important to note that siblings and mothers were inclined to repeat their previous behaviors, which resulted in higher transitional probabilities from sibling-to-sibling and motherto-mother behaviors than from sibling/mother behaviors to infant behaviors. For example, the transitional probability that an infant would respond to a sibling/mother behavior with an iov, idn, or idv was less than .1 for both infant- 
sibling and infant-mother interactions. However, the probability that a sibling/ mother would respond to her own behavior ranged from .25 to .45 .

\section{Discussion}

As predicted, level of responsiveness to infant behaviors was age-related. An analysis of level of responsiveness to infant behaviors revealed that the way older siblings interact with their infant siblings comes to resemble the interactive style of their mothers after age 6. More specifically, siblings in the 3-6 years age group had difficulty attuning to the infant and did not provide a significant amount of responsive feedback. Although siblings, in general, tended to respond to infant behaviors with non-responsive other behaviors, 3- to 6-year-old siblings displayed non-responsive behaviors more often. Older siblings, aged 7 to 10 years old, were more responsive to infant behaviors and they exhibited levels of responsiveness similar to those of their mothers.

Given that 7- to 10-year-olds differed from 3- to 6-year-olds in responsiveness to object-related behaviors but not dyadic behaviors, types of responsive caregiving behaviors may also develop with age. Younger siblings responded to infant dyadic behaviors (i.e., behaviors directed at them), but not to infant behaviors directed at objects. Thus, younger siblings were more adept at engaging in dyadic interactions than they were at participating in object-related joint attention activities. Although they responded to face-to-face interactions, younger siblings were more inclined to play with one object while infants played with another object; younger siblings showed a preference for playing with their own toys. Occasionally, sibling object-related responsiveness occurred because the sibling wanted an object that the infant was playing with, which required the sibling to focus on the same object as the infant.

In particular, siblings engaged in more other, non-responsive behaviors and provided infants with an interaction environment that was substantially different from the environment provided by mothers. Mothers, in contrast, responded to both object-related and dyadic infant behaviors. Moreover, infants were less vocal during interactions with siblings as compared to mothers. Infants also emitted more responsive behaviors during infant-mother interactions. Mothers' responsiveness may have encouraged infants to respond in kind and also be more responsive. In contrast, siblings' lack of responsiveness limited the amount of interaction between siblings and infants; siblings did not respond to infant behaviors, thus infants were less likely to exhibit behaviors that would encourage a sibling response.

An analysis of family demographics indicated that siblings who read to infants, attended school, were required to babysit, or had mothers who worked inside the home were more responsive to infant behaviors. Although having a mother who spent a majority of her time at home caring for the family may have provided more opportunities for older siblings to engage in observational learning of behaviors, the influence of other types of interactions show that siblings learn interaction behaviors from multiple sources. Reading aloud, 
participating in school activities, and babysitting all require siblings to engage in social behaviors which may, in turn, foster their ability to interact responsively with infants. Skills that may be enhanced include turn-taking, prosocial responsiveness, joint attention, and monitoring the body language, facial expressions, and mood of one's interaction partner.

Although it can be argued that children learn a majority of their responsiveness and caregiving behaviors via observational learning, it can also be argued that older siblings do not learn these behaviors through the observation of infant-mother interactions. Instead, older siblings may learn through their own experiences with their mothers (i.e., they learn to interact with their children in a manner which is similar to the way their parents interacted with them). If this is the case, then personal experience should be added as an additional source of responsiveness and caregiving behaviors. To test this source, we would need to conduct a longitudinal study with children who have siblings and children who do not to see which family model results in the greatest intergenerational transmission of responsiveness and caregiving behaviors.

\section{Limitations and Future Directions}

While the present study has a number of strengths in that it has provided insight into when and how siblings model the behaviors of their mothers, it also has some limitations. For example, an assessment of gender revealed that the responsiveness behavior of male and female siblings was not significantly different. It is possible that the siblings in this study were too young to allow for an accurate assessment of gender differences. These differences may become more apparent during adolescence when children are developing their identities, exploring their gender status, participating in gender-typical school and home activities, and displaying more gender-typed behaviors. An assessment of maternal responsiveness for siblings older than 10 years of age would help clarify the age at which gender differences emerge during infant-sibling interactions.

A longitudinal, in-home study that follows multiple families would be beneficial in that it would provide a continuous record of responsiveness and caregiving behaviors. Furthermore, a longitudinal study would provide additional insight into the effects that differences in sibling age, household size, birth order, and sibling spacing have on the trajectory of responsiveness and caregiving behaviors. A longitudinal study could also be used to evaluate the types of caregiving behaviors that are transmitted from one generation to the next. Do other mutually exclusive behaviors emerge with increases in family size or access to family members from multiple generations? What other familial situations provide older siblings with opportunities to learn responsiveness and caregiving behaviors? Are ethnicity and socio-economic status influential factors in the intergenerational transmission of caregiving behaviors?

The majority of the participants in this study were white and from middle to upper-middle class families. Different behavioral and responsiveness patterns may emerge if this study were conducted with families of different socio- 
economic and cultural backgrounds (see e.g., Kärtner et al. 2010, Klarin et al. 2014, Rabain-Jamin 2001, Tanaka et al. 2009). Additionally, in cultures (e.g., the Wolof of Senegal; Rabain-Jamin 2001) where older siblings are expected to do a majority of the caregiving, even younger siblings may be more responsive to infant behaviors. If that is the case, we would expect to see fewer differences between age groups and an earlier emergence of caregiver-like responsiveness levels in cultures where sibling childrearing is common.

Knowing the onset of caregiving behaviors would help identify a timeframe in which a positive caregiving intervention would be most helpful for at-risk families. Through the exploration of infant-sibling interactions, behavioral research can shed light on how to design intervention programs for caregivers and children in at-risk families. The interventions would focus on responsive, positive caregiving in contrast to harsh, negative caregiving. By combining our knowledge of which positive behaviors are displayed during infant-caregiver and infant-sibling interactions, we can develop interventions that are doubly beneficial in that they increase responsiveness to infant behaviors and further the intergenerational transmission of positive, learning enhancing caregiving behaviors.

The mutually exclusive categories of behaviors employed herein provide a useful way to assess the behaviors of families from a myriad of cultures and backgrounds. The technique offers an easy way to explore infant-sibling and infant-mother interactions without requiring the assumption that only primary caregivers provide responsive caregiving behaviors. The categories are also beneficial to the study of the intergenerational transmission of caregiving behaviors in that the behaviors analyzed are not culture specific. Thus, they provide a measure of flexibility that other responsiveness and caregiving behavior categories may not offer.

\section{Acknowledgements}

This research was supported by a National Science Foundation Graduate Research Fellowship awarded to Tywanquila Walker. I would like to thank Taijha Holder, Erin Malley, Halley Siegal, Sylvia Sable, and Tingting Wu for their help with participant recruitment, data collection, and coding. I also wish to thank the families for their participation.

\section{References}

Bailey JA, Hill KG, Oesterle S, Hawkins DJ (2009) Parenting practices and problem behavior across three generations: Monitoring, harsh discipline, and drug use in the intergenerational transmission of externalizing behavior. Developmental Psychology 45: 1214-1226.

Bakeman R, Quera V (1995) Log-linear approaches to lag-sequential analysis when consecutive codes may and cannot repeat. Psychological Bulletin, 118: 272-284. 
Bandura A, Huston A (1961) Identification as a process of incidental learning. Journal of Abnormal and Social Psychology 63(2): 311-318.

Bandura A, Ross D, Ross S (1961) Transmission of aggression through imitation of aggressive models. Journal of Abnormal and Social Psychology 63(3): 575-582.

Baumrind D (1991) Parenting styles and adolescent development. In J Brooks-Gunn, R Lerner, AC Petersen (Eds) The Encyclopedia on Adolescence. New York: Garland.

Bobbitt RA, Gourevitch VP, Miller LE, Jensen, G.D. (1969) Dynamics of social interactive behavior: A computerized procedure for analyzing trends, patterns, and sequences. Psychological Bulletin 71(2): 110-121.

Bornstein MH, Tamis-LeMonda CS, Tal J, Ludemann P, Toda S, Rahn C, Pêcheux M, Azuma H, Vardi D (1992) Maternal responsiveness to infants in three societies: The United States, France, and Japan. Child Development 63: 808-821.

Cancian M, Reed D (2009) Changes in family structure, childbearing, and employment: Implications for the level and trend in poverty. In M Cancian, S Danziger (Eds) Changing poverty. New York: Russell Sage Foundation.

Casillas M (2014) Turn-taking. In D Matthews (Ed) Pragmatic development in first language acquisition, 53-70. Amsterdam: Benjamins.

Chen ZY, Kaplan HB (2001) Intergenerational transmission of constructive parenting. Journal of Marriage and the Family 63: 17-31.

Crouter AC, Manke BA, McHale SM (1995) The family context of gender intensification in early adolescence. Child Development 66: 317-329.

DuMont K, Rodriguez M, Mitchell-Herzfeld S, Walden N, Kirkland K, Greene R, Lee E (2008) Effects of Healthy Families New York on maternal behaviors: Observational assessments of positive and negative parenting. Rensselaer, New York: New York State Office of Children and Family Services.

Dunn J, Munn P (1986) Siblings and the development of prosocial behavior. International Journal of Behavioral Development 9(3): 265-284.

Dunn J, Shatz M (1989) Becoming a conversationalist despite (or because of) having an older sibling. Child Development 60: 399-410.

Eisenberg N, Lennon R, Roth K (1983) Prosocial development: A longitudinal study. Developmental Psychology 19(6): 846-855.

Eisenberg N, Shell R, Pasternack J, Belter R, Lennon R, Mathy RM (1987) Prosocial development in middle childhood: A longitudinal study. Developmental Psychology 23(5): 712-718.

Fisher C, Sanderson P (1996) Exploratory sequential data analysis: Exploring continuous observational data. Interactions 3(2): 25-34.

Galambos NL, Almeida DM, Petersen AG (1990) Masculinity, femininity, and sex role attitudes in early adolescence: Exploring gender intensification. Child Development 61: 1905-1914.

Goldstein MH, Brodsky P (2006) EventCoder [computer software]. Ithaca: Cornell University.

Gros-Louis JG, West M J, Goldstein MH, King AP (2006) Mothers provide differential feedback to infants' prelinguistic sounds. International Journal of Behavioral Development 30: 509-516.

Haebig E, McDuffie A, Weismer SE (2013) The contribution of two categories of parent verbal responsiveness to later language for toddlers and preschoolers on the autism spectrum. American Journal of Speech-Language Pathology 22: 5770 .

Hetherington ME (1994) Siblings, family relationships, and child development: Introduction. Journal of Family Psychology 8: 251-253. 
Hofmann T, Puzicha J, Jordan MI (1999) Learning from dyadic data. In Advances in Neural Information Processing Systems 11, 466-472. Cambridge, MA: MIT Press.

Howe N (1991) Sibling-directed internal state language, perspective taking, and affective behavior. Child Development 62: 1503-1512.

Jeong A (2005) A guide to analyzing message-response sequences and group interaction patterns in computer-mediated communication. Distance Education 26: 367-383.

Kärtner J, Keller H, Yovsi RD (2010) Mother-infant interaction during the first 3 months: The emergence of culture-specific contingency patterns. Child Development 81: 540-554.

Klarin M, Proroković A, Šimunić A (2014) The role of intergenerational transmission of parenting in close relationships of male and female adolescents. Mediterranean Journal of Social Sciences 5: 1821-1832.

Kogan KL, Wimberger HC (1966) An approach to defining mother-child interaction styles. Perceptual and Motor Skills 23: 1171-1177.

Leaper C (2000) Gender, affiliation, assertion, and the interactive context of parentchild play. Developmental Psychology 36(3): 381-393.

Leaper C (2002) Parenting girls and boys. In MH Bornstein (Ed) Handbook of Parenting: Vol. 1. Children and parenting (2nd ed.). Mahwah, NJ: Erlbaum.

Lii SY (1981) The group comparison of different sequential behavioral analyses on dyadic interaction. The Journal of Experimental Education 50(18): 18-24.

Madden V, Domoney J, Aumayer K, Sethna V, Iles J, Hubbard I, Giannakakis A, Psychogiou L, Ramchandani P (2015) Intergenerational transmission of parenting: Findings from a UK longitudinal study. The European Journal of Public Health 25(3): 1-6.

Neppl TK, Conger RD, Scaramella LV, Ontai LL (2009) Intergenerational continuity in parenting behavior: Mediating pathways and child effects. Developmental Psychology 45: 1241-1256.

O'Connor BP (1999) Simple and flexible SAS and SPSS programs for analyzing lagsequential categorical data. Behavior Research Methods, Instrumentation, and Computers 31: 718-726. Retrieved from http://bit.ly/2usVT46.

Olson G M, Herbsleb JD, Rueter HH (1994) Characterizing the sequential structure of interactive behaviors through statistical and grammatical techniques. HumanComputer Interaction 9: 427-472.

Pan R (2010) A gentle introduction to the analysis of sequential data. American Society for Quality (ASQ) Statistics Division Newsletter 28(1): 4-8.

Putallaz M, Costanzo PR, Grimes CL, Sherman DM (1998) Intergenerational continuities and their influences on children's social development. Social Development 7: 389427.

Rabain-Jamin J (2001) Language use in mother-child and young sibling interactions in Senegal. First Language 21(63): 357-385.

Sawin DB, Langlois JH, Leitner EF (1977) What do you do after you say hello? Observing, coding, and analyzing parent-infant interactions. Behavior Research Methods and Instrumentation 9: 425-428.

Schofield T J, Weaver JM (2016) Democratic parenting beliefs and observed parental sensitivity: Reciprocal influences between coparents. Journal of Family Psychology 30: 509-515.

Seay DM, Jahromi LB, Umaña-Taylor AJ, Updegraff KA (2016) Intergenerational transmission of maladaptive parenting strategies in families of adolescent mothers: Effects from grandmothers to young children. Journal of Abnormal Child Psychology 44: 1097-1109. 
Serbin L, Karp J (2003) Intergenerational studies of parenting and the transfer of risk from parent to child. Current Directions in Psychological Science 12: 138-142.

Shatz M, Gelman R (1973) The development of communication skills: Modifications in the speech of young children as a function of listener. Monographs of the Society for Research in Child Development 38(5): 1-38.

Sigel IE, Parke RD (1987) Structural analysis of parent-child research models. Journal of Applied Developmental Psychology 8: 123-137.

Simons RL, Beaman J, Conger RD, Chao W (1993) Gender differences in the intergenerational transmission of parenting beliefs. Journal of Marriage and the Family 54: 823-836.

Simons RL, Whitbeck LB, Conger RD, Wu C (1991) Intergenerational transmission of harsh parenting. Developmental Psychology 27: 159-171.

Tamis-LeMonda CS, Bornstein MH (2002) Maternal responsiveness and early language acquisition. Advances in Child Development and Behavior 29: 89-127.

Tanaka M, Kitamura T, Chen Z, Murakami M, Goto Y (2009) Do parents rear their children as they were reared themselves? Intergenerational transmission of parental styles (warmth and control) and possible mediation by personality traits. The Open Family Studies Journal 2: 82-90.

U.S. Census Bureau (2010) Table AVG2. Average number of people per family household, by race and Hispanic origin, marital status, age, and education of householder: 2010. Retrieved from http://bit.ly/2tst6fN. [Accessed 23 April 2011].

Vollmer L (2007) Developmental changes in infants' knowledge of the instrumental value of babbling. Unpublished honors thesis, Cornell University, Ithaca, NY.

Wineberg H, McCarthy J (1989) Child spacing in the United States: Recent trends and differentials. Journal of Marriage and the Family 51(1): 213-228.

Zukow-Goldring P (2002) Sibling caregiving. In MH Bornstein (Ed) Handbook of Parenting: Vol. 3: Being and becoming a parent (2nd ed.). Mahwah, NJ: Erlbaum. 
